\title{
Biocontrole de doenças de parte aérea do tomateiro por Nocardioides thermolilacinus
}

\author{
Renato Carrer Filho, Reginaldo S. Romeiro \& Flávio Augusto O. Garcia \\ Departamento de Fitopatologia, Universidade Federal de Viçosa, 36.571-000, Viçosa, MG, Brasil
}

Autor para correspondência: Reginaldo S. Romeiro, e-mail: rromeiro@ufv.br

\begin{abstract}
RESUMO
A cultura do tomate demanda de um elevado número de aplicação de agrotóxicos, os quais podem ser perigosos tanto para o ambiente como para o homem. Assim, esse trabalho visa avaliar a eficácia da actinobactéria Nocardioides thermolilacinus, estirpe SON-17, como agente de biocontrole de doenças do tomateiro quando dispensado no filoplano de plantas. Inicialmente, a potencialidade foi checada in vitro contra Alternaria solani, Corynespora cassiicola, Phytophthora infestans, Pseudomonas. syringae pv. tomato, Xanthomonas campestris pv. vesicatoria. A estirpe SON-17 não inibiu o crescimento das bactérias, mas inibiu a germinação de esporos fúngicos. No ensaio em casa de vegetação, quando plantas de tomate foram atomizadas com suspensão de propágulos de SON-17 e quatro dias após inoculadas com patógenos desafiantes, o antagonista foi hábil em reduzir a severidade de A. solani, S. solani, C. cassiicola, X. campestris pv. vesicatoria e P. syringae pv. tomato. Em condições de campo, quando o actinomiceto foi dispensado semanalmente por atomização, a severidade da pinta preta foi reduzida em comparação com o controle. A estirpe SON-17 deve ser melhor investigada como agente de biocontrole de doenças do tomateiro.
\end{abstract}

Palavras-chave: Controle biológico, antagonismo microbiano, actinobactéria.

\begin{abstract}
Biocontrol of foliar disease of tomato plants by Nocardioides thermolilacinus

Tomato needs a large number of applications of pesticides, which can be dangerous both for the environment and for humans. This paper aimed to evaluate the efficiency of actinobacteria Nocardioides thermolilacinus, strain SON-17, as a biocontrol agent for tomato diseases when delivered to the phylloplane of tomato plants. In a first approach, its in vitro antagonistic potential was checked against the pathogens Alternaria solani, Corynespora cassiicola, Phytophthora infestans, Pseudomonas. syringae pv. tomato, Xanthomonas campestris pv. vesicatoria. Strain SON-17 did not inhibit growth of bacterial pathogens but inhibited spore germination of the fungal ones. In greenhouse assays, when tomato plants were sprayed with a propagule suspension of SON-17 and four days later inoculated with challenging pathogens, the agent was able to reduce disease severity in the case of the pathogens A. solani, S. solani, C. cassiicola, X. campestris pv. vesicatoria and $P$. syringae pv. tomato. In field trials, when actinomycete was weekly applied by spraying, the severity of early blight was reduced in comparison with the controls. Strain SON-17 deserves further investigation as a biocontrol agent for tomato diseases.
\end{abstract}

Keywords: Biological control, microbial antagonism, actinobacteria.

A cultura do tomate é atacada por inúmeros fitopatógenos, mais de 200 já foram descritos, sendo que alguns como Alternaria solani e Phytophthora infestans podem inviabilizar o cultivo da planta em determinadas condições (Jones et al., 1991). Isso leva ao uso de grandes quantidades de agrotóxicos na cultura, sendo a maioria prejudicial aos ecossistemas, bem como seus resíduos em frutos são sérias ameaças à saúde humana (Barreto \& Scaloppi, 2000). Na busca por métodos de menor impacto, o controle biológico é uma das alternativas mais promissoras.

Dentre os vários organismos utilizados no biocontrole, as actinobactérias veem sendo testadas e em alguns casos com promissores resultados (Romeiro, 2007). Actinobactérias são organismos pertencentes ao domínio Bacteria, grampositivas, de crescimento filamentoso, podendo formar pseudomicélio, sendo algumas espécies formadoras de endósporos (Madigan et al., 2003). As espécies do gênero
Nocardioides são actinobactérias posicionadas no grupo VI actinobactérias filamentosas geralmente encontradas em solos, com parede celular densa e formadoras de endósporos (Madigan et al., 2003). A formação dessa estrutura permite a sobrevivência do agente de biocontrole a situações desfavoráveis ao seu desenvolvimento, como temperaturas elevadas, estresse hídrico. Sendo sobrevivência uma característica desejável a um agente de biocontrole.

A estirpe SON-17 de Nocardioides thermolilacinus $\mathrm{Lu}$ et Yan, foi originalmente isolada de rizosfera de plantas de tomateiro, e posteriormente demonstrou ser um bom agente de biocontrole de doenças da cultura, quando dispensado nesse habitat, por meio de microbiolização de sementes (Carrer Filho, 2002), não havendo relato anterior do uso desse organismo como agente de biocontrole de doença de plantas. O presente trabalho tem como objetivo, avaliar a eficácia da estirpe SON 17 de $N$. thermolilacinus 
como agente de biocontrole de doenças da parte aérea do tomateiro.

Os microrganismos utilizados foram: $N$. thermolilacinus, Stemphylium solani G.F. Weber, Alternaria solani Sorauer, Corynespora cassiicola (Berk. \& M.A. Curtis) C.T. Wei, Phytophthora infestans (Mont.) de Bary, Pseudomonas syringae pv. tomato (Okabe) Young, Dye \& Wilkie, Xanthomonas vesicatoria (Doidge) Vauterin et al., oriundos da coleção de culturas do Departamento de Fitopatologia da UFV. Os patógenos fúngicos foram cultivados em BDA, à exceção de $S$. solani em que utilizou o meio V8-Agar (Tuite, 1969) e as bactérias em meio 523 (Kado \& Heskett, 1970). Após multiplicação, as culturas foram preservadas sob óleo mineral (Smith \& Onions, 1994) a $4^{\circ} \mathrm{C}$. A estirpe SON-17 de $N$. thermolilacinus foi cultivada e mantida em meio de extrato de solo-ágar (Pramer \& Schmidt, 1964).

No ensaio de inibição da germinação de conídios uma suspensão aquosa de propágulos do antagonista $N$. thermolilacinus $\left(\mathrm{OD}_{540}=0,6\right)$ foi depositada na superfície de uma lâmina comum de microscopia e misturada com igual volume de suspensão de conídios de $A$. solani $(5 \mathrm{x}$ $10^{3}$ conídios. $\left.\mathrm{mL}^{-1}\right)$ ou $S$. solani $\left(10^{4}\right.$ conídios. $\left.\mathrm{mL}^{-1}\right)$ ou $C$. cassiicola $\left(10^{4}\right.$ conídios. $\left.\mathrm{mL}^{-1}\right)$. Como controles utilizaramse água e suspensão do fungicida clorotalonil ( 2 g.L $\left.{ }^{-1}\right)$. Para cada tratamento, foram utilizadas três repetições. As lâminas foram mantidas em câmara úmida, a $28^{\circ} \mathrm{C}$, por 24 horas e a germinação quantificada pela contagem de 100 conídios por lâmina.

O efeito de $N$. thermolilacinus sobre a inibição da liberação de zoósporos de $P$. infestans também foi avaliado, utilizando o procedimento descrito por Halfeld-Vieira (2002), em que a solução salina $(\mathrm{NaCl} 0,14 \mathrm{M})$ e a solução do fungicida clorotalonil ( 2 g. $\left.\mathrm{L}^{-1}\right)$, foram usadas como controle. Uma suspensão aquosa de esporângios de $P$. infestans $\left(10^{4}\right.$ esporângios. $\mathrm{mL}^{-1}$ ), foi preparada a partir de frutos verdes de tomateiro, previamente inoculados e mantidos em câmara úmida. Cinqüenta (50) $\mu \mathrm{L}$ desta suspensão foram depositados na superfície de lâmina comum de microscopia e misturados com igual volume de suspensão de propágulos da estirpe SON-17 $\left(\mathrm{OD}_{540}=0,6\right)$. As lâminas foram mantidas a $4^{\circ} \mathrm{C}$ por 3 horas e, após, a $17^{\circ} \mathrm{C}$ por 24 horas. $\mathrm{O}$ ensaio foi conduzido com três repetições, contando-se 100 esporângios por repetição.

A técnica de dupla camada (Romeiro, 2001) foi utilizada para observar a capacidade de $N$. thermolilacinus em inibir o crescimento das bactérias $P$. syringae pv. tomato e $X$. vesicatoria. Para tanto, o antagonista foi cultivado em meio 523 (Kado \& Heskett, 1970) líquido por 18 horas, sendo após vertido $10 \mu \mathrm{L}$ em um ponto central de placa de Petri contendo o meio 523 (Kado \& Heskett, 1970) sólido, incubando-se por 48 horas, a $28^{\circ} \mathrm{C}$. Em câmara de fluxo laminar, as placas foram destampadas e expostas à radiação UV $(254 \mathrm{~nm})$ por 15 minutos. Sobre esse meio verteu-se a respectiva cultura da fitobactéria em teste, após homogenização de $0,1 \mathrm{~mL}$ da fitobactéria na fase exponencial de crescimento em meio semi-sólido fundente, formando uma sobrecamada de $1 \mathrm{~mm}$ de espessura. As placas foram mantidas a $28^{\circ} \mathrm{C}$ e inspecionadas diariamente, observandose os halos de inibição. O ensaio foi conduzido com três repetições, uma placa de Petri para cada repetição.

Estudos de biocontrole em casa de vegetação foram conduzidos a fim de averiguar o controle de patógenos fúngicos e bacterianos, in vivo. Os experimentos foram conduzidos em delineamento inteiramente casualizado, com 10 repetições, sendo que cada repetição consistiu em um vaso de $500 \mathrm{~mL}$ contendo como substrato solo não esterilizado, areia e matéria orgânica (6:2:1) com duas plantas. Uma suspensão aquosa de propágulos da estirpe SON-17 $\left(\mathrm{OD}_{540}=0,3\right)$, preparada a partir da cultura na fase exponencial de crescimento (aproximadamente 20 horas), foi dispensada por atomização na parte aérea de plantas de tomateiro cultivar Santa Cruz Kada, $5 \mathrm{~mL}$ por planta, aos 35 dias após a semeadura. Após quatro dias as plantas foram mantidas em câmara úmida por $24 \mathrm{~h}$ e, a seguir, inoculadas com os respectivos patógenos, em separado, nas seguintes concentrações de inoculo: $P$. syringae pv. tomato $\left(\mathrm{OD}_{540}=\right.$ $0,2) ;$ C. cassiicola $\left(2 \times 10^{4}\right.$ conídios $\left.\mathrm{mL}^{-1}\right) ;$ S. solani $(2,5$ x $10^{3}$ conídios $\left.\mathrm{mL}^{-1}\right)$, A solani $\left(2 \times 10^{4}\right.$ conídios $\left.\mathrm{mL}^{-1}\right) \mathrm{e}$ $X$. vesicatoria $\left(\mathrm{OD}_{540}=0,1\right)$. Avaliando-se a severidade de doença, por meio da escala de Horsfall \& Barrat (1945), adaptado de Campbell \& Madden (1990).

O biocontrole em condições de campo foi testado em um experimento realizado no delineado em quatro blocos com cinco plantas por parcela, foi instalado em uma área experimental do campus da Universidade Federal de Viçosa onde tomate é cultivado continuamente. Mudas obtidas em estufa com 20 dias de idade, foram atomizadas com suspensão de propágulos do agente de biocontrole $\left(\mathrm{OD}_{540}\right.$ $=0,3)$ e transplantadas no espaçamento $0,60 \mathrm{~m}$ entre linhas e $0,30 \mathrm{~m}$ nas linhas. Semanalmente, até cerca de cinco semanas após o transplante das mudas, repetia-se a aplicação do antagonista $\left(\mathrm{OD}_{540}=0,3\right)$, por atomização do filoplano com aproximadamente $35 \mathrm{~mL}$ por planta. Monitorou-se a ocorrência de doenças da parte aérea, sendo avaliada a severidade de $A$. solani, semanalmente, pelo uso da escala diagramática desenvolvida por Boff et al. (1991) e um painel de três avaliadores. Água e o fungicida clorotalonil $\left(2 \mathrm{~g} \mathrm{~L}^{-1}\right)$ foram usados como controles.

Os resultados mostram que ouve inibição no percentual de germinação de esporos de $A$. solani (Água = $65,66 \%$ A, Fungicida $=3 \%$ B, SON-17 6,66\% B), S. solani (Água $=38 \%$ A, Fungicida $=3,66 \%$ B, SON-17 8,33\% B) e C. cassiicola $($ Água $=60 \% \mathrm{~A}$, Fungicida $=1 \%$ B, SON -17 $16,66 \%$ B) e de liberação de zoósporos de P. infestans (Água $=28 \%$ A, SON-17 10,33\% B, Fungicida $=0,66 \%$ C). Para bactérias não foi detectada inibição in vitro. Antagonismo in vitro, como observado pela estirpe SON-17, entre microrganismos é fenômeno comum (Madigan et al., 2003). Porém, sua aplicação a campo nem sempre é reproduzível.

A estirpe SON-17, quando dispensada no filoplano de plantas de tomateiro, cultivado em casa de vegetação, 
reduziu a severidade de lesões por folíolos tanto de patógenos fúngicos (C. cassiicola, A. solani, S. solani) como bacterianos (P. syrinage pv. tomato e $X$. campestris pv. vesicatoria) em relação à testemunha (Figura 1). A ausência de atividade antagonística in vitro contra as fitobactérias, deve-se possivelmente às limitações do teste de antibiose por dupla camada. O teste avalia apenas o mecanismo de antibiose, porém existem outros mecanismos possíveis como a produção de sideróforos, a competição por nutrientes e por nichos ecológicos e a interferência com o fenômeno de "quorum sensing" (Romeiro, 2007). De fato, a estirpe SON-17 foi capaz de promover o controle biológico em casa de vegetação e contra múltiplos patógenos. Assim, há necessidade de estudar os outros mecanismos, bem como averiguar se o controle é reproduzido em condições de campo, uma vez que organismos que se mostram promissores em condições de casa de vegetação fracassam quando levados a campo (Chiou \& Wu, 2003; Steddom et al., 2002).

No ensaio a campo, a avaliação da área abaixo da curva de progresso de pinta preta causado por A. solani, demonstrou que o fungicida $(8,50 \%)$ foi o tratamento mais eficiente no controle da doença. Porém, em relação ao controle $(106,66 \%)$ o antagonista $(55,63 \%)$ reduziu significativamente o progresso da pinta preta, confirmando sua eficácia como agente de biocontrole. Isto sugere que a estirpe SON-17 possa ser utilizado como parte das medidas de manejo integrado que poderia tornar possível a redução da quantidade de fungicidas aplicados e/ou aumentar o espaço entre pulverizações.

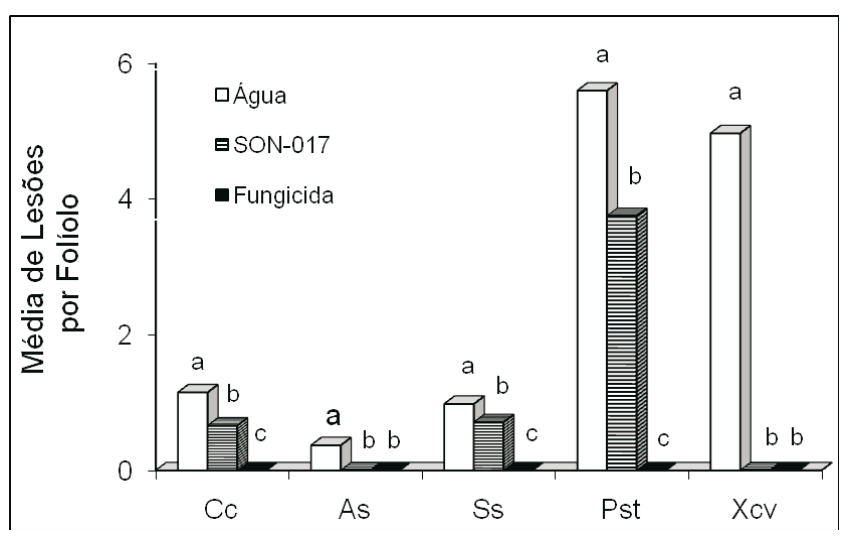

FIG. 1 - Média de lesões por folíolo em plantas de tomateiro de doenças causadas pela inoculação de patógenos Cc- Corynespora cassiicola; As- Alternaria solani; Pst- Pseudomonas syringae pv. tomato; Ss- Stenphylium solani; Xcv-X. campestris pv. vesicatoria, em plantas atomizadas com propágulos de Nocardioides thermolilacinus estirpe SON-17, ou com o fungicida clorotalonil. Água representa o tratamento controle. Valores seguidos pela mesma letra não diferem entre si pelo teste Tuckey ao nível de 0,01 de probabilidade.
Não foi possível verificar a eficácia da estirpe SON17 sobre demais doenças do tomateiro devido a ocorrência de uma forte epidêmia de requeima ( $P$. infestans), sobre o qual a actinobactéria não teve efeito. A ausência de controle da requeima, indica que possivelmente, o biocontrole possa não ser a principal estratégia de controle, para doenças as quais o agente etiológico seja patógenos de alta agressividade como $P$. infestans, mas demonstra potencial para o seu uso como medidas de manejo de outras doenças do tomateiro, como foi o caso da pinta preta.

\section{AGRADECIMENTOS}

Os autores expressam seus agradecimentos à Fundação de Amparo à Pesquisa do Estado de Minas Gerais - FAPEMIG e ao Conselho Nacional de Desenvolvimento Científico e Tecnológico - CNPq pelo financiamento parcial deste trabalho.

\section{REFERÊNCIAS BIBLIOGRÁFICAS}

Barreto M, Scaloppi EG (2000) Sistemas de previsão de hortaliças. In: Zambolim L (Ed.) Manejo integrado-doenças, pragas e plantas daninhas. Viçosa MG. Suprema Gráfica e Editora. pp. 169-186.

Boff P, Vale FXR, Zambolim L, Fontes PCR (1991) Epidemiologia comparativa da mancha-de-estenfílio (Stemphylium solani) e da pinta-preta (Alternaria solani), em dois sistemas de condução do tomateiro. Fitopatologia Brasileira 16:104-109.

Campbell CL, Madden LV (1990) Introduction to plant disease epidemiology. New York. John Wiley \& Sons.

Carrer Filho R (2002) Actinobactérias como agentes de biocontrole de doenças e como promotores de crescimento do tomateiro. Dissertação de Mestrado. Viçosa MG. Universidade Federal de Viçosa.

ChiouAL, WuWS(2003)Formulation of Bacillus amyloliquefaciens B190 for control of lily grey ould (Botrytis elliptica). Journal of Phytopathology 151:13-18.

Halfeld-Vieira BA (2002) Bactérias residentes do filoplano de tomateiro como agentes de controle biológico de enfermidades da parte aérea da cultura. Tese de Doutorado. Viçosa MG. Universidade Federal de Viçosa.

Jones JP, Stall RE, Zitter TA (1991) Compendium of Tomato Diseases. Saint Paul MN. APS Press.

Kado CI, Heskett MG (1970) Selective media for isolation of Agrobacterium, Corynebacterium, Erwinia, Pseudomonas and Xanthomonas. Phytopathology 60: 969-979.

Madigan MM, Martinko J, Parker JE (2003) Brock Biology of Microorganisms, 10‥ Ed. New York NY. Prentice Hall.

Pramer D, Schmidt EL (1964) Experimental Soil Microbiology. Saint Paul MN. Burgess Publishing Company.

Romeiro RS (2001) Métodos em bacteriologia de plantas. Viçosa MG. Editora UFV. 
Romeiro RS (2007) Controle Biológico de Doenças de Plantas Fundamentos. Viçosa MG. Editora UFV.

Smith D, Onions AHS (1994) The preservation and maintenance of living fungi. Surrey UK. International Mycological Institute.

Steddom K, Menge JA, Crowley D, Borneman J (2002) Effect of repetitive applications of the biocontrol bacterium Pseudomonas putida 06909-rif/nal on Citrus Soil Microbial Communities. Phytopathology. 92:857-862.

Tuite J (1969) Plant pathological methods, Fungi and bacteria. Minneapolis. Burgess Publishing Company.

Recebido 17 Março 2008 - Aceito 28 Dezembro 2008 - TPP 7032

Editor Associado: Wagner Bettiol 